\title{
Defining Key Performance Indicators for Evaluating the Use of High Definition Video-to-Video Services in eHealth
}

\author{
Andreea Molnar and Vishanth Weerakkody \\ Brunel University Business School \\ Uxbridge, Middlesex UB8 3PH \\ \{andreea.molnar, vishanth.weerakkody\}@brunel.ac.uk
}

\begin{abstract}
This paper examines the process of developing key performance indicators (KPIs) for evaluating the use of high definition video (HD) to video (V2V) communication for tele-monitoring patients in a healthcare setting. The research is performed in the context of the European Commission funded LiveCity project and uses as a case study the monitoring of glaucoma patients using V2V technology. Initially, a set of KPIs are defined for V2V use in eHealth services based on literature and secondary research and these KPIs are then refined based on interviews with medical staff involved in the treatment of glaucoma patients. The obtained KPIs are used to analyse the potential of using $\mathrm{V} 2 \mathrm{~V}$ services in the context of tele-monitoring glaucoma patients.
\end{abstract}

Keywords: high definition video, eHealth, tele-monitoring, glaucoma, KPIs.

\section{Introduction}

In the current economic climate, where governments are under constant pressure to deliver 'better for less', the role and impact that Information and Communication Technology (ICT) has on core public services such as healthcare has increased more than ever before. In particular, most European governments see ICT as a means to facilitate and improve health services and as a mechanism to reduce the cost associated with healthcare service delivery [1, 2, 3, 4]. Among the variety of existing health services, in this paper, we focus on tele-monitoring and we argue that it is possible to improve the quality and acceptance of existing tele-monitoring services by using HD $\mathrm{V} 2 \mathrm{~V}$ communication. This research is performed in the context of the LiveCity project (EU FP7 CIP grant agreement No. 297291), and focuses on the case of tele monitoring for glaucoma patients.

Although tele-monitoring is not necessarily a new concept, problems are reported due to image noise and jerky sound that may be crucial for the proper diagnosis of patients [5]. In this context, the LiveCity project aims to ensure that HD V2V communication is provided between the hospital and the patient. This is of particular importance for the LiveCity case study, as it involves communication with glaucoma patients, and in this case, for a consultation, high quality images are imperative [6]. However, the technical details on providing high quality video are out of the scope of this paper, as this paper focuses on the evaluation of tele-monitoring services through V2V by defining a set of KPIs. 
In order to do so, the paper is structured as follows: The next section sets the background of this research. It is followed by a brief introduction on how delivery of HD V2V services can be facilitated over public infrastructure. The next section then briefly introduces the evaluation phases of the LiveCity project, followed by an initial set of KPIs for eHealth services. This is followed by the main results of a semi-structured interview that was conducted to collect data from a doctor treating glaucoma patients. The paper then concludes by offering a discussion of the results, conclusions and future work.

\section{Background}

Using ICT in health services (electronic health - eHealth) has been seen as a solution for reducing the cost associated with healthcare delivery [2], improving decision making to increase the quality of service offered to patients, improving the access to information [7], and contributing to the saving of lives through advanced tools and techniques [8]. However, the adoption of ICT in healthcare has not met initial expectations with reports of poor take up by both practitioners and patients $[9,10]$. Prior research has identified several issues with the current use of e-Health such as the communication infrastructure $[1,10]$, the necessity for the system to be user centric [11], and the need to involve stakeholders from the initial stages of service design [1].

Several services that have been used in e-health, such as Electronic Health Records (EHRs) [12, 13], picture archiving and communication system, and tele-medicine [14] as core services that are enabled by ICT. This research focuses on a particular type of tele-medicine/tele-monitoring, and explores the use of HD V2V between the patient and the hospital. Tele-monitoring has been used for the monitoring of patients suffering from a wide range of diseases such as: diabetes, hypertension, home delivery, home nursing care for elderly and chronically ill, and glaucoma, either through the use of voice or voice and video communication $[15,16]$. In this paper we address telemonitoring for glaucoma patients. Glaucoma is one of the major causes of blindness worldwide and its treatment requires frequent monitoring of patients [17]. When the communication between patient and doctor has been done through $\mathrm{V} 2 \mathrm{~V}$, prior research shows that although there is no cost saving between a tele-monitoring consultation and one in the hospital, patients were often satisfied with their personal cost and time savings that came as a consequence of using the system [18]. Among the drawbacks reported for remote consultation, poor image quality appears as one of the biggest issues impeding tele-monitoring.

Problems with the image quality have also been observed in conventional telemedicine [19]. Such problems have resulted in adequate information not being available for proper diagnosis of patients [5]. In a more recent study, Bradford et al. [20] reported that problems with poor video quality in tele-monitoring contexts have led the nurse "to use a mobile phone for audio and the Internet video call for visual communication only, as the quality of the video could be improved by allowing more bandwidth" [20]. In this respect, LiveCity aims to alleviate the problems that exist with the delivery of video over public internet infrastructure and facilitate the delivery of high definition video for the eHealth context as part of its portfolio. 


\section{Using High Definition Video in Tele-monitoring: LiveCity}

As previous studies performed on video to video communication for tele-monitoring reported various difficulties encountered when delivering video over the Internet, such as poor image and noise quality [5], the LiveCity project aims to alleviate the problems that the transmission of high definition video over public Internet infrastructure faces, through the use of a Virtual Path Slice (VPS) controller (Fig. 1). While it is not our intention to discuss the technical characteristics and functions of the VPS controller in this paper, essentially it is an application that manages bandwidth by avoiding interference from unwanted traffic and therefore ensuring that any loss of delivered data and delays are reduced [21]. It therefore creates a virtual path over the public Internet to allow traffic (data, voice and video) to flow freely without losing quality. This ensures that signals are not interrupted by other external Internet traffic when the connection between two points of contact is established, therefore guaranteeing the transmission of high quality live video images between two points of contact.

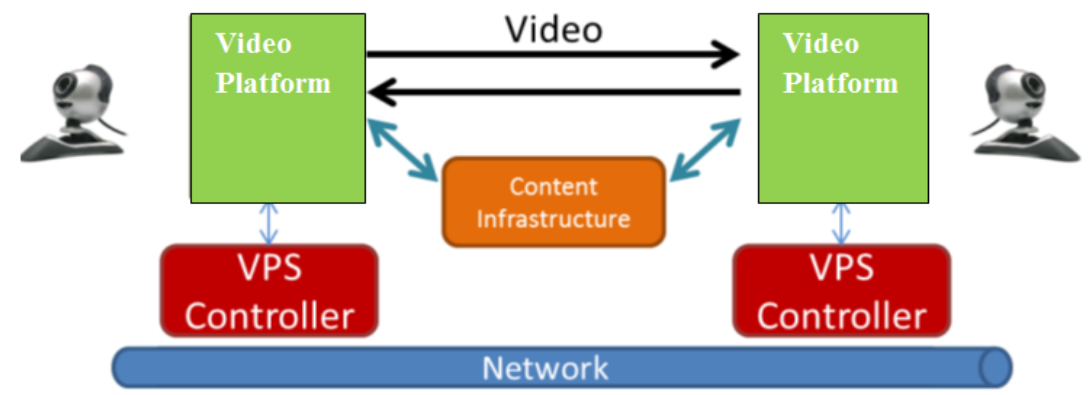

Fig. 1. Video Platform with the Use of VPS Controller [21]

Transmission of HD V2V is particularly important for certain consultations for which the medical staff need to see detailed information. In this respect, the quality of images need to be very good, as is the case of glaucoma patients, where a high quality picture of the eye is necessary for a proper diagnosis [6]. Glaucoma treatment usually consists on applying eye-drops, this being the preferred treatment to an operation. The treatment requires taking the medication in the same dose at the appropriate time and proper application of the eye-drops. However, it is reported that almost half of the patients fail to apply the eye drops correctly [6], resulting in improper treatment of glaucoma leading to complications, side effects, eye-damage and vision loss. In such circumstances the communication between the doctor and the patient is extremely important for the success of the treatment. However, due to various reasons, such as convenience, cost or impossibility to arrive at a hospital premises or private clinic, communication and/or consultation between the patients and the healthcare provider can sometimes be difficult. This is especially significant in cases where patients are unable to physically visit their doctor due to disability or old age, or for those people 
living in remote locations. In this respect, tele-monitoring could help in consulting glaucoma patients and checking whether they take their treatment properly. In this paper we focus on the first phase of evaluating the tele-monitoring of glaucoma patients using HD V2V in the context of the LiveCity project and defining the KPIs to be used in the second phase for assessing the success of tele-monitoring in this context.

\section{Evaluation}

The purpose of the evaluation is to determine relevant Key Performance Indicators (KPIs) for successful adoption of video-to-video tele-monitoring for glaucoma patients. The LiveCity evaluation consists of two phases [22]. In the first phase, KPIs are determined. During the second phase, the obtained KPIs from the first phase are being applied to assess the LiveCity use case (in this case, the treatment of glaucoma patients using V2V tele-monitoring) and revise the KPIs. The revised KPIs will result in final recommendations for designing and implementing $\mathrm{V} 2 \mathrm{~V}$ tele-monitoring services for glaucoma patients.

The research presented in this paper focuses on the first phase. During this phase an initial set of KPIs are identified, followed by a revision of the originally obtained KPIs based on stakeholders consultations (in this case, interviews with doctors). The importance of involving relevant stakeholders in the implementation of ICT in public services in general [23] [12], and understanding doctors' perception of using HD V2V communication in particular is imperative before such services are implemented in healthcare settings to facilitate their adoption.

In this respect, it is important to find out what criteria are necessary to facilitate a successful adoption of HD V2V communication as proposed in the LiveCity project in the context of a healthcare setting. With this aim, we performed a preliminary interview with a doctor treating glaucoma patients at a large University Clinic hospital in Attica, Greece. This is the place where the LiveCity pilot will take place and the interviewed doctor will be involved in tele-monitoring glaucoma patients.

The interview was semi-structured with open-ended questions. Semi-structured interviews are the most common used tool in qualitative research in information systems [24]. The interview was conducted in April 2013 and tape recorded with the doctor's permission. Since the purpose of this study was focused on the initial exploration of the concept of $\mathrm{V} 2 \mathrm{~V}$ used for the tele-monitoring of glaucoma patients, and not generalisation, a single in-depth interview was deemed adequate to fulfil the overall aim of the study.

\subsection{Initial KPIs}

In Table 1, we present the initial Use Case related KPIs we perceive to be important for evaluating the LiveCity platform, as drawn from the literature and consultation with LiveCity project partners. The technical KPIs related to the network connectivity and application are not presented in this paper as they are general to every LiveCity services and have been previously covered in $[22,25]$. The remaining KPIs have been organised into user requirements and process requirements. 
Table 1. Initial Health KPIs

\begin{tabular}{|c|c|c|}
\hline \multirow{14}{*}{ 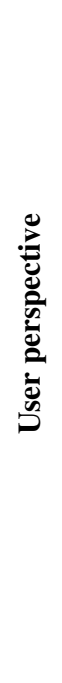 } & \multicolumn{2}{|r|}{ Health KPIs } \\
\hline & \multirow{6}{*}{ 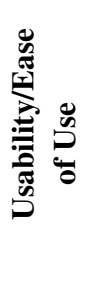 } & Ease of use \\
\hline & & Navigation \\
\hline & & Help features \\
\hline & & Background and colour \\
\hline & & User involvement in parameterization \\
\hline & & Menu simplicity \\
\hline & \multirow{4}{*}{ 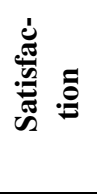 } & Delighted with systems \\
\hline & & Pleased with the system \\
\hline & & Satisfied with the system \\
\hline & & Image quality \\
\hline & \multirow{3}{*}{ 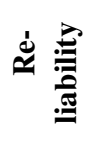 } & Number of interruptions during a session \\
\hline & & Boot time for the application \\
\hline & & Response time \\
\hline \multirow{21}{*}{ 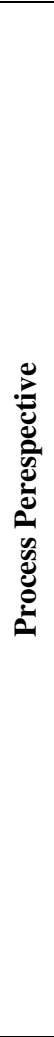 } & \multicolumn{2}{|c|}{ Anonymity of sensitive data } \\
\hline & \multicolumn{2}{|c|}{ Encryption of Sensitive data and communication } \\
\hline & \multicolumn{2}{|c|}{ Data storage in a physically secure location } \\
\hline & \multicolumn{2}{|c|}{ Data Security } \\
\hline & \multicolumn{2}{|c|}{ System development cost } \\
\hline & \multicolumn{2}{|c|}{ Time for examination } \\
\hline & \multicolumn{2}{|c|}{ Hospital resources committed for the new system } \\
\hline & \multicolumn{2}{|c|}{ Learning time for new system use } \\
\hline & \multicolumn{2}{|c|}{ Time-to-doctor: meeting the doctor and starting the examination } \\
\hline & \multicolumn{2}{|c|}{ Physical presence cost including transfer to the hospital } \\
\hline & \multicolumn{2}{|c|}{ Waiting time in the hospital for examination } \\
\hline & \multicolumn{2}{|c|}{ Number of patients involved in the pilot } \\
\hline & \multicolumn{2}{|c|}{ Number of visits to the hospital (emergency) } \\
\hline & \multicolumn{2}{|c|}{ Number of visits to the hospital (outpatient) } \\
\hline & \multicolumn{2}{|c|}{ Waiting time in the hospital (emergency visit) } \\
\hline & \multicolumn{2}{|c|}{ Waiting time in the hospital (outpatient appointment) } \\
\hline & \multicolumn{2}{|c|}{ Number of patients } \\
\hline & \multicolumn{2}{|c|}{ Conformance to treatment } \\
\hline & \multicolumn{2}{|c|}{ Intraocular pressure control } \\
\hline & \multicolumn{2}{|c|}{ Ease of appointment scheduling (time required) } \\
\hline & \multicolumn{2}{|c|}{ Ease of appointment scheduling (ease of set up) } \\
\hline
\end{tabular}


User Requirements: these are related to the actual utilisation of the V2V service by the involved users and the respective level of user experience. KPIs are built around:

- Usability/Ease of Use: V2V services shall be easy to use by different classes of users,

- Satisfaction: captures the different levels of user experience,

- Reliability: reflects user point of view regarding reliability aspects of the $\mathrm{V} 2 \mathrm{~V}$ provision.

Process Requirements: these are related to the end-to-end process tailored to the various $\mathrm{V} 2 \mathrm{~V}$ provision scenarios. In this case, in Table 1, we outline examples of the specific use case related KPIs for delivering health services using V2V.

\subsection{Refining the KPIs: Interview with the Doctor}

After defining the initial KPIs from literature and secondary research, we conducted an in-depth interview with the doctor involved in treating glaucoma patients and who will be testing the tele-monitoring HD V2V solution offered by the LiveCity project. The purpose of this interview was to assess the criteria that are most important from his (the doctor's) point of view for the successful adoption of $\mathrm{V} 2 \mathrm{~V}$ in treating glaucoma patients. The interviewed doctor worked at the University Hospital Clinic responsible for treating (including performing surgical operations) patients with glaucoma in the Attica region as well as from across Greece who commute to the hospital for check-ups and treatment. In this particular case, it is anticipated that telemonitoring using $\mathrm{HD} \mathrm{V} 2 \mathrm{~V}$ will facilitate better patient conformance to the right treatment and correct application of the eye-drops with the remote assistance from their doctor. Moreover, it is hoped that V2V will help patients access medical information remotely when needed and have their questions or queries answered with regards to their treatment. In the scope of the proposed activities, doctors will be able to interact with their patients and will be able to monitor them allowing frequent patient consultation during the medical treatment process. The high quality of live V2V will eliminate the necessity for patients to travel and visit their hospital and will allow doctors to monitor how patients apply their eye-drops and guide them to take corrective action when necessary. The necessity of refining the KPIs is motivated by the fact that the quality of service is mostly context dependent $[26,27,28]$, with prior research showing failed attempts to measure it using general scales in new contexts [29].

The interview with the doctor took place in April 2013. As a result of the interview, additional items were created and qualitative findings were matched with the existing scales to match construct definitions. During the interview, the doctor highlighted the importance of some of the initial KPIs presented in Table 1, such as the importance of patient satisfaction with the system, "....if they [patients] are happy themselves, the patients who use the technology are satisfied, they will like it, will use it or we may even lose them in the process". In this process, the Doctor emphasised that the "video quality is the most important thing" due to the neccessity to see a detailed picture of the human eye. 
Table 2. New KPIs Identified for tele-monioring of Glaucoma Patients using V2V

\begin{tabular}{|c|c|c|}
\hline & Criteria & Interview quote \\
\hline & Improvement in the patients' health & $\begin{array}{l}\text { "if they do not follow the treatment correctly, the } \\
\text { eye will be lost" }\end{array}$ \\
\hline & Reduce the medication cost & $\begin{array}{l}\text { "if they put their drops correctly, maybe they need } \\
\text { less bottles, less medicine, less eye drops... this } \\
\text { means they do not pay extra money for medicine } \\
\text { they do not need to use... often a lot of medicine is } \\
\text { wasted because patient do not know how to use it" }\end{array}$ \\
\hline & $\begin{array}{|lll|}\begin{array}{l}\text { Improved doctor } \\
\text { communication }\end{array} & / & \text { patient } \\
\end{array}$ & "follow our patients more closely" \\
\hline & $\begin{array}{l}\text { Improved monitoring of patients } \\
\text { by doctors }\end{array}$ & $\begin{array}{l}\text { "We [doctors] are always worried whether they } \\
\text { [patients] use the drops correctly" } \\
\text { "Patients underestimate the difficulty to put a drop } \\
\text { into the eye, so we [doctors] can see them [patients] } \\
\text { in their home and how they use the eye drops" }\end{array}$ \\
\hline : & $\begin{array}{l}\text { Improvement in the availability } \\
\text { /easiness for patients to reach } \\
\text { doctors }\end{array}$ & $\begin{array}{l}\text { "in case they [patients] want to ask something as an } \\
\text { emergency ... they will find it easier this way" } \\
\text { "patients often complain that when they want to } \\
\text { reach us [doctors], it is very difficult to get an } \\
\text { appoitment" } \\
\text { "through the V2V solution, they [patients] find it } \\
\text { more easy to reach us" }\end{array}$ \\
\hline 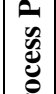 & $\begin{array}{l}\text { Improve patient perception of doctor } \\
\text { availability }\end{array}$ & $\begin{array}{l}\text { "feeling that we [doctors] are available for } \\
\text { them [patients]" }\end{array}$ \\
\hline 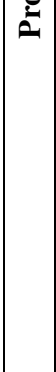 & Improvement in patient management & $\begin{array}{l}\text { "we [doctors] can decide whether they [patients] } \\
\text { need to came or they can stay at home and continue } \\
\text { the treatment... This will help to reduce } \\
\text { transportation costs" } \\
\text { "..So many times they [patients] do not need to } \\
\text { come to the hospital...it would be even better for us } \\
\text { to decide if they need to come.... I believe that } \\
\text { patient management as a result of using the system } \\
\text { would be extremely better with V2V... not just } \\
\text { better" }\end{array}$ \\
\hline & $\begin{array}{l}\text { Improvement in the number of } \\
\text { patients treated }\end{array}$ & $\begin{array}{l}\text { "due to the improved patient management and less } \\
\text { appointments and physical consultations, we will be } \\
\text { able to treat more patients" }\end{array}$ \\
\hline & $\begin{array}{l}\text { Improve } \quad \text { the } \quad \text { patient } \\
\text { skills/knowledge in applying their } \\
\text { eye drops }\end{array}$ & $\begin{array}{l}\text { "Patients underestimate the difficulty of putting a } \\
\text { drop into the eye"... "they [patients] need to be } \\
\text { trained, educated, and reminded" }\end{array}$ \\
\hline & $\begin{array}{l}\text { Patient reliability in getting the } \\
\text { treatment correctly }\end{array}$ & $\begin{array}{l}\text { "Ideally we would realise that patients who have } \\
\text { been educated for the first month with more } \\
\text { consultations, appoitments, video to video } \\
\text { consultations could be more reliable with the } \\
\text { treatment afterwards" }\end{array}$ \\
\hline
\end{tabular}




\section{Discussions, Conclusions and Future Work}

One of the clear benefits of using V2V enabled tele-monitoring is the ability to treat patients without the need for physical consultation and the need to be transported to a hospital. This could be particularly important for patients living in remote locations where access to the hospital is difficult, or for the elderly (who are most prone to be affected by glaucoma and require usually to be accompanied to the hospital) by allowing them to be independent for a longer period of time without the need to commute to the hospital.

The purpose of this paper was to determine a set of KPIs aimed at assessing telemonitoring services for glaucoma patients. With this aim, we first identified generic KPIs from the literature, secondary sources and through consultation with the involved partners in the LiveCity project. This was followed by an interview with a doctor treating glaucoma patients at a large hospital in Athens, Greece. We presented the KPIs identified initially as well as the new ones obtained as a result of the interview.

From a theoretical perspective this study extends service quality research by developing a set of indicators for tele-monitoring patients who suffer from glaucoma. The implications of this research are highly relevant to the decision makers of eHealth platforms who are offering tele-monitoring services for glaucoma patients. These findings improve the general understanding of how doctors evaluate service quality in the context of glaucoma treatment using tele-monitoring. The proposed indicators should contribute to paving the way for conducting effective design of service delivery systems in the context of eHealth services.

Several limitations in this paper are worth noting. This research was conducted in only one country, and by interviewing only one doctor responsible for treating glaucoma patients. Replication in other contexts would increase the confidence in the proposed indicators; hence, the findings should be treated as indicative rather than confirmatory.

Once the V2V system is implemented for tele-monitoring of glaucoma patients in the context of the LiveCity project, we propose to refine the KPIs during the implementation and testing of the system and consequently propose a framework for evaluating the V2V enabled tele-monitoring of health services. The obtained KPIs and framework will then be used as a source to develop a 'how to' guide for delivering V2V based eHealth services.

Acknowledgments. The authors acknowledge the contributions made to this article by the LiveCity consortium of partners who are funded by the European Commission, especially to NKUA for helping in organising the study presented in the paper.

\section{References}

1. Charles, B.L.: Telemedicine can Lower Costs and Improve Access. Healthcare Financial Management 54(4), 66-69 (2000)

2. Dorsey, E.R., Venkataraman, V., Grana, M.J., Bull, M.T., George, B.P., Boyd, C.M., Beck, C.A., Rajan, B., Seidmann, A., Biglan, K.M.: Randomized Controlled Clinical Trial of "Virtual House Calls" for Parkinson Disease "Virtual House Calls" for Parkinson Disease. JAMA Neurology, 1-6 (2013) 
3. Porter, M.E., Teisberg, E.O.: Redefining Health Care: Creating Value-based Competition on Results. Harvard Business School Press, USA (2006)

4. Stefanou, C., Revanoglou, A.: ERP Integration in a Healthcare Environment: A Case Study. Journal of Enterprise Information Management 19(4), 115-130 (2006)

5. Shimizu, S., Okamura, K., Nakashima, N., Kitamura, Y., Torata, N., Yamashita, T.: High-Quality Telemedicine using Digital Video Transport System over Global Research and Education Network. In: Georgi Graschew, G. (ed.) Roelofs TAAdvances in Telemedicine: Technologies, Enabling Factors and Scenarios, pp. 87-110. Intech, Croatia (2011)

6. Stamatelatos, M., Katsikas, G., Makris, P., Alonistioti, N., Antonakis, S., Alonistiotis, D., Theodossiadis, P.: Video-to-video for e-health: Use case, concepts and pilot plan. In: Iliadis, L., Maglogiannis, I., Papadopoulos, H., Karatzas, K., Sioutas, S. (eds.) AIAI 2012 Workshops, Part II. IFIP AICT, vol. 382, pp. 311-321. Springer, Heidelberg (2012)

7. Lenz, R., Kuhn, K.A.: Towards a Continuous Evolution and Adaptation of Information Systems in Healthcare. International Journal of Medical Informatics 73(1), 75-90 (2004)

8. Haughom, J.L.: Implementation of an Electronic Health Record. In: BMJ, p. 343 (2011)

9. Atherton, H., Azeem, M.: An Information Revolution: Time for the NHS to Step up to the Challenge. JRSM 104(6), 228-230 (2011)

10. Cresswell, K., Aziz, S.: The NHS Care Record Service (NHS CRS): Recommendations from the Literature on Successful Implementation and Adoption. Informatics in Primary Care 1(3), 153-160 (2009)

11. Westrup, C.: What's in Information Technology. Asian Institute of Technology, Bangkok (1998)

12. Currie, W.L.: Evaluating the Governance Structure for Public Sector IT: The UK National Programme in the Health Service. Evaluating Information Systems, 199-217 (2012)

13. Lafky, D., Tulu, B., Horan, T.: Information Systems and Health Care X: A User Driven Approach to Personal Health Records. Comm. of the Association for IS 17, 1028-1041 (2006)

14. Menachemi, N., Burke, D.E., Ayers, D.J.: Factors Affecting the Adoption of Telemedicine-A Multiple Adopter Perspective. Journal of Medical Systems 28(6), 617-632 (2004)

15. Hjelm, N.M.: Benefits and Drawbacks of Telemedicine. Journal of Telemedicine and Telecare 11(2), 60-70 (2005)

16. Kassam, F., Yogesan, K., Sogbesan, E., Pasquale, L.R., Damji, K.F.: Teleglaucoma: Improving Access and Efficiency for Glaucoma Care. Middle East African Journal of Ophthalmology 20(2), 142 (2013)

17. Poon, C.C.Y., Wang, M.D., Bonato, P., Fenstermacher, D.A.: Editorial: Special Issue on Health Informatics and Personalized Medicine. IEEE Transactions on Biomedical Engineering 60(1), 143-146 (2013)

18. Tuulonen, A., Ohinmaa, A., Alanko, H.I., Hyytinen, P., Juutinen, A., Toppinen, E.: The Application of Teleophthalmology in Examining Patients with Glaucoma: A Pilot Study. Journal of Glaucoma 8(6), 367-373 (1999)

19. Demartines, N., Mutter, D., Vix, M., Leroy, J., Glatz, D., Rösel, F., Harder, F., Marescaux, J.: Assessment of Telemedicine in Surgical Education and Patient Care. Annals of Surgery 231(2), 282

20. Bradford, N., Armfield, N.R., Young, J., Ehmer, M., Smith, A.C.: Safety for Home Care: The Use of Internet Video Calls to Double-Check Interventions. Journal of Telemedicine and Telecare 18(8), 434-437 (2012) 
21. Chochliouros, I.P.: Description and Thematic Context of the LiveCity Project. In: Conference of Telecommunication, Media and Internet Techno-Economics. Workshop on Network Operators View on Future Networks Landscape: Will it be Cloudy with a Chance of Data Rain, Internet (2012), http: / / www . ctte-conference.org/files /

2011/CTTE_OperatorsWorkshop_Chochliouros_LiveCity.pdf (cited February 4, 2013)

22. Weerakkody, V., El-Haddadeh, R., Chochliouros, I.P., Morris, D.: Utilizing a high definition live video platform to facilitate public service delivery. In: Iliadis, L., Maglogiannis, I., Papadopoulos, H., Karatzas, K., Sioutas, S. (eds.) AIAI 2012 Workshops, Part II. IFIP AICT, vol. 382, pp. 290-299. Springer, Heidelberg (2012)

23. Goel, S., Dwivedi, R., Sherry, A.: Role of Key Stakeholders in Successful E-Governance Programs: Conceptual Framework. In: Proceedings of the Eighteen American Conference on Information Systems, Seattle, Washington, USA, August 9-11 (2012), http: / /aisel.aisnet.org/amcis2012/proceedings/EGovernment/19/

24. Myers, M.D., Newman, M.: The Qualitative Interview in IS Research: Examining the Craft. Information and Organization 17(1), 2-26 (2007)

25. Weerakkody, V., Molnar, A., Irani, Z., El-Haddadeh, R.: A Research Proposition for Using High Definition Video in Emergency Medical Services. Health Policy and Technology 2(3), 131-138 (2013), http: / dx.doi.org/10.1016/j.hlpt.2013.04.001

26. Babakus, E., Boller, G.W.: An Empirical Assessment of the SERVQUAL Scale. Journal of Business Research 24(3), 253-268 (1992)

27. Carman, J.M.: Consumer Perceptions of Service Quality: An Assessment of the SERVQUAL Dimensions. Journal of Retailing (1990)

28. Dabholkar, P.A., Thorpe, D.I., Rentz, J.O.: A Measure of Service Quality for Retail Stores: Scale Development and Validation. Journal of the Academy of Marketing Science 24(1), 3-16 (1996)

29. Dagger, T.S., Sweeney, J.C., Johnson, L.W.: A Hierarchical Model of Health Service Quality Scale Development and Investigation of an Integrated Model. Journal of Service Research 10(2), 123-142 (2007) 